\title{
Vulnerability and access to care for South Asian Sikh and Muslim patients with life limiting illness in Scotland: prospective longitudinal qualitative study
}

\author{
Allison Worth, senior research fellow, ${ }^{1}$ Tasneem Irshad, research fellow, ${ }^{1}$ Raj Bhopal, Bruce and John Usher \\ professor of public health, ${ }^{1}$ Duncan Brown, consultant in palliative medicine, ${ }^{2}$ Julia Lawton, senior research \\ fellow, ${ }^{1}$ Elizabeth Grant, research fellow, ${ }^{1}$ Scott Murray, professor, ${ }^{1}$ Marilyn Kendall, research fellow, ${ }^{1}$ \\ James Adam, consultant in palliative medicine, ${ }^{3}$ Rafik Gardee, former director, ${ }^{4}$ Aziz Sheikh, professor of \\ primary care research and development ${ }^{1}$
}

\begin{abstract}
Primary Palliative Care Research Group, Centre for Population Health Sciences, University of Edinburgh, Edinburgh EH8 9DX

${ }^{2}$ St Columba's Hospice, Edinburgh

${ }^{3}$ Marie Curie Hospice, Glasgow

${ }^{4}$ National Resource Centre for Ethnic Minority Health, Glasgow

Correspondence to: A Sheikh

Aziz.Sheikh@ed.ac.uk
\end{abstract}

Cite this as: $B M J$ 2009;338:b183 doi:10.1136/bmj.b183

\section{ABSTRACT}

Objectives To examine the care experiences of South Asian Sikh and Muslim patients in Scotland with life limiting illness and their families and to understand the reasons for any difficulties with access to services and how these might be overcome.

Design Prospective, longitudinal, qualitative design using in-depth interviews.

Setting Central Scotland.

Participants 25 purposively selected South Asian Sikh and Muslim patients, 18 family carers, and 20 key health professionals.

Results 92 interviews took place. Most services struggled to deliver responsive, culturally appropriate care. Barriers to accessing effective end of life care included resource constrained services; institutional and, occasionally, personal racial and religious discrimination; limited awareness and understanding among South Asian people of the role of hospices; and difficulty discussing death. The most vulnerable patients, including recent migrants and those with poor English language skills, with no family advocate, and dying of non-malignant diseases were at particularly high risk of inadequate care.

Conclusions Despite a robust Scottish diversity policy, services for South Asian Sikh and Muslim patients with life limiting illness were wanting in many key areas. Active case management of the most vulnerable patients and carers, and "real time" support, from where professionals can obtain advice specific to an individual patient and family, are the approaches most likely to instigate noticeable improvements in access to high quality end of life care. Improving access to palliative care for all, particularly those with non-malignant illnesses, as well as focusing on the specific needs of ethnic minority groups, is required.

\section{INTRODUCTION}

In palliative care the dominant notion of a good death is based on a patient being fully aware of their diagnosis and prognosis and able to engage in advance care planning. This does not, however, necessarily reflect different social, cultural, and spiritual beliefs and practices around death and dying as expressed by ethnic minority groups and faith groups. ${ }^{1}$ In some communities, for example, the diagnosis of a life limiting illness is not openly discussed and end of life decisions are more family focused. ${ }^{23}$ Considerations about faith have often been overlooked in research, and end of life needs in minority groups remain poorly understood. $^{24-7}$

In the United States and the United Kingdom people from ethnic minority communities access proportionately fewer palliative care services than the majority population, although deficits in recording ethnicity and socioeconomic status make it difficult to determine accurately the extent of inequalities and inequities in care. ${ }^{28-14}$ We use the term access to incorporate more than accessibility-it requires patients to be able to actually make use of appropriate and high quality care. Factors contributing to poor access to palliative care services include low numbers of referrals of patients from ethnic minority communities to palliative care; lack of knowledge and awareness of palliative care among ethnic minority groups; communication difficulties between service providers and users, including language barriers; mistrust and dissatisfaction with services; and lack of accessible information leading to misunderstandings around the nature of the illness and prognosis. ${ }^{3114-18}$ Family carers too are disadvantaged by poor access to services, with impact on their physical and mental health, employment, and educational opportunities. $^{19}$

Access to specialist palliative care services remains predominantly focused on cancer. Services for those with non-cancer illnesses are largely provided by generalists, who may be less aware of the need for a palliative care approach. ${ }^{162021}$ Epidemiological studies indicate that the incidence of cancer is lower among migrants to the UK than the overall population, but it is rising. ${ }^{2223}$ Rates of other life limiting illnesses, such as 
coronary heart disease, cardiovascular disease, and diabetes are, however, comparatively higher than in the population overall. ${ }^{1024}$ These differences in disease risk among ethnic groups may also contribute to the lower access to palliative care experienced by ethnic minority groups.

South Asian Sikh and Muslim communities are among the largest, established ethnic minority groups in the UK and Europe. These migrant communities, which began arriving in large numbers in the aftermath of the second world war, are now ageing, with important implications for service provision. Understanding their end of life needs is an important first step in developing appropriate, equitable, and accessible care services for all and in making palliative care a credible and attractive choice for South Asians. ${ }^{4}$

We studied the care experiences and needs of South Asian Sikh and Muslim patients with life limiting illness and of their families from the perspectives of the patient, family carer, and key health professionals. Through understanding the barriers and facilitators to accessing services identified by participants in our study, and relating these to the wider theoretical literature and policy, we aimed to inform service developments.

Box 1: Definitions of ethnicity, race, faiths, and languages of participants

\section{Ethnicity}

The social group someone belongs to and either identifies with or is identified with by others as a result of a mix of cultural and other factors, including one or more of language, diet, religion, ancestry, and physical textures traditionally associated with race

\section{Race}

The group someone belongs to as a result of a mix of physical features such as skin colour and hair texture, which reflect ancestry and geographical origins, as identified by others or, increasingly, self identified

\section{Racism or institutional racism}

A belief that some races are superior to others, used to devise and justify individual and collective actions that create and sustain inequality among racial and ethnic groups. Individual racism is usually manifested in decisions and behaviours that disadvantage small numbers of people. Institutional racism, where policies and traditions, sometimes unwittingly, favour a particular racial or ethnic group, may be less obvious but may disadvantage large populations

\section{Languages}

Punjabi-the language of a region encompassing north western India and northern Pakistan; the main spoken language of Pakistani Muslims who have migrated to the UK, and the mother tongue of most Indian Sikhs

Urdu - the official language of Pakistan, widely used by Pakistani Muslims in written form Gurmukhi-the written language of many Indian Sikhs

Faith

Muslim -The name given to a follower of the religion of Islam, the main tenets of which are monotheism, prophethood, and life after death

Sikh-The name given to a follower of Sikhism, which has at its root the notion of learning; core beliefs include monotheism and reincarnation

\section{South Asian}

Someone whose ancestry is in the countries of the Indian subcontinent, including India, Pakistan, Bangladesh, and Sri Lanka

Adapted from Bhopal ${ }^{13}$

\section{METHODS}

The projected sample size of 20-25 participants was determined by experience of previous longitudinal qualitative studies, ${ }^{2025}$ which led us to believe that this would generate sufficient data to answer the research questions. We purposively recruited South Asian Sikh and Muslim patients with cancer and other life limiting conditions who were believed to have a prognosis of less than a year. Box 1 gives definitions of ethnicity, race, faiths, and languages of participants. Recruitment among ethnic minority groups is known to be challenging ${ }^{426}$ and we therefore planned a combination of approaches to patients through healthcare and social care professionals, community leaders, and personal contacts of the research team in local Sikh and Muslim communities. The composition of the research team was in part guided by this need. The researchers approached health professionals, community and religious leaders, and volunteer workers to identify eligible individuals they knew to have advanced incurable illness. They then gave an information sheet about the project to the potential participant in English as well as in Gurumukhi or Urdu, depending on their country of origin or religious affiliation. If they expressed interest in taking part, the patient's name was passed to the research team. The trilingual researcher (TI) explained the study verbally and obtained written consent in the language of each participant's choice. Consent was reconfirmed verbally before each interview, carried out at intervals of three or four months. Patients were asked to nominate a family carer and the health professional most involved in their support and care, and these individuals were approached and gave consent separately. If no new insights emerged during the second interview, patients were contacted by telephone before the third interview and, if their circumstances were unchanged, were not interviewed again.

\section{Data generation}

TI interviewed the patients and family carers, mainly at home and in a language of their choice. Most were interviewed in Punjabi (18 patients, 10 carers) and the remainder in English (5 patients, 7 carers) and Urdu (2 patients, 1 carer). TI and AW interviewed service providers, mainly by telephone. Up to three in-depth, semistructured interviews were carried out with each participant over 18 months. Box 2 shows the topics discussed in the interviews. If appropriate, interviews after bereavement were carried out with family and professional carers 8-12 weeks after death. We assessed patients' functional status at each interview using the performance scale of the Eastern Cooperative Oncology Group ${ }^{27}$ and reviewed case notes for background data. A researcher and a trilingual secretary recorded, transcribed, and translated the interviews when necessary; to ensure contextual accuracy translated transcripts were checked against recorded interviews by bilingual members of the research team. 


\section{Box 2: Topics discussed in interviews}

\section{Interviews with patients}

- History of the illness

- Impact of the illness on quality of life and how the patient has coped with it

- Main needs (physical, psychological, social) in the past year and currently

- Cultural, religious, and spiritual needs, and the role of faith and traditions in managing illness*

- How well needs are met

- Expectations of the future*

- Care preferences and care received

- Relationships with service providers

- Perceptions of services such as hospital and hospice care

- Death and dying (if patients wish to discuss this)

- The negotiation process whereby care options are pursued at various points in the patient's illness*

- Decision making in the family*

- Palliative care services: availability, appropriateness, and acceptability*

- Suggestions for improving care*†

Interviews with family carers

- History from family carer perspective

- Impact of the illness on the carer, wider family, and social network and how they have coped with it

- Carer's perspective of patient's main needs over the past year and currently, and how well these are met

- Carer's own needs and how well these are met

- Death and dying (if family carers wish to discuss this)

- Family carer's preferences for care, and perspectives of care received

Interviews with service providers

- Involvement with patient and family

- Perceptions of patient's and family's needs and how well these are met

- Services provided by self and others

- Communication with patient and family about end of life needs

*Also discussed with family carers.

†Also discussed with service providers. to ensure that death and dying were not inappropriately discussed during interviews. In reporting data we took additional steps to disguise participants' identities and maintain confidentiality.

\section{RESULTS}

In all, 25 of $26(96 \%)$ people identified as having life limiting illness agreed to participate. In addition, 18 carers and 20 healthcare and social care professionals were recruited. The total dataset comprised 92 interviews. Patients had either a primary diagnosis of cancer $(n=11)$ or other long term illnesses $(n=14)$. Participants were younger (mean age 59 (SD 14.7) years) than those typically recruited into other studies on end of life ${ }^{2025}$ and had younger families, reflecting the younger age profile of ethnic minority groups in the UK. Seven patients were Sikhs and 18 were Muslims, reflecting the relative size of these populations in Scotland. ${ }^{30}$ Most lived in nuclear or extended families, with only three living alone. Six patients died during the study. The family carers nominated were predominantly women, with seven wives, five daughters, and four daughtersin-law taking part in the study, along with four husbands and one son. Four patients had no family carer and a further three carers declined to participate. Among the range of professionals nominated, most $(n=13)$ were general practitioners. Others included consultants, specialist nurses, social workers, and one hospital manager. Table 1 summarises the patients' characteristics and table 2 summarises the interviews with family carers and professional carers.

The experiences of South Asian Sikh and Muslim patients and their families were, in many respects, similar to those identified in other end of life studies in the general population. ${ }^{16202532}$ Box 3 summarises these overlapping themes. Box 4 summarises the experiences more evident in the South Asian participants in this study.

\section{Accessing effective end of life care}

Only two patients, both with advanced cancer, accessed specialist palliative care services, and both received high quality care. Both died in a hospice, where the patients and their family carers reported that staff showed exceptional willingness to learn about and meet their particular needs. It seemed that the individualised care philosophy of the hospice resulted in appropriate, responsive end of life care:

“This hospice has been very good to us. They've said if there's anything you need, tell us. They've gone out and got halal meat. Anything we've wanted, they've gone and got." (Carer 20, wife of Muslim patient with cancer, stage 1 interview)

Aspects of hospice care that were particularly valued by patients and carers included appropriate dietary provision, prayer facilities, provision of Asian TV channels, setting up of a video telephone enabling patients to speak to relatives in Pakistan, support for families, help accessing benefits, and care after bereavement.

\section{Ethical considerations}

We ensured that participants understood the study sufficiently to give informed consent, particularly as some were unable to read. When participants were unaware of poor prognosis or diagnosis, care was taken 
Two other patients who were not yet terminally ill reported coordinated and well managed palliative care (box 5), one led by oncology services and one, for a patient with non-cancer illness, by social services. Both these patients were highly articulate, assertive, and knowledgeable about services, and took a leading role in determining the course of their treatment and the type of services they received. They were also relatively young women with children at home.

\section{Barriers to effective end of life care}

Many patients, particularly those with a non-cancer illness, did not seem to receive care based on either management of a long term condition or palliative care.

\begin{tabular}{|c|c|c|c|c|c|c|c|c|c|}
\hline Participant & $\begin{array}{l}\text { Primary } \\
\text { diagnosis }\end{array}$ & Age category & Sex & Religion & $\begin{array}{l}\text { ECOG score at } \\
\text { each stage }\end{array}$ & $\begin{array}{c}\text { Deprivation } \\
\text { category } \dagger\end{array}$ & Status & Home situation & $\begin{array}{c}\text { Timing of } \\
\text { interviews with } \\
\text { patient }\end{array}$ \\
\hline P01 & Cancer & $51-60$ & Male & Muslim & 4,4 & 2 & Asylum seeker & Nuclear family & $\begin{array}{l}\text { Stages } 1 \ddagger \text { and } 2 \text {; } \\
\text { patient died }\end{array}$ \\
\hline P02 & Cancer & $61-70$ & Male & Muslim & 3 & 6 & UK citizen & Nuclear family & $\begin{array}{l}\text { Stage 1ł; patient } \\
\text { died }\end{array}$ \\
\hline P03 & Cancer & $30-40$ & Female & Muslim & $3,2,2$ & 1 & UK citizen & Nuclear family & Stages 1-3 \\
\hline P04 & $\begin{array}{l}\text { Non-malignant } \\
\text { illness }\end{array}$ & $41-50$ & Female & Muslim & $4,4,4$ & 4 & UK citizen & Nuclear family & Stages 1-3 \\
\hline P05 & Leukaemia & $30-40$ & Female & Muslim & $2,3,2$ & 7 & UK citizen & Nuclear family & Stages $1 \neq, 2$, and 3 \\
\hline P06 & $\begin{array}{l}\text { Non-malignant } \\
\text { illness }\end{array}$ & $41-50$ & Male & Sikh & $1,1,1$ & 7 & Asylum seeker & Alone & Stages 1-3 \\
\hline P07 & Cancer & $61-70$ & Male & Muslim & $2,2,2$ & 4 & UK citizen & Alone & Stages 1-3 \\
\hline P08 & $\begin{array}{l}\text { Non-malignant } \\
\text { illness }\end{array}$ & $61-70$ & Male & Muslim & 3,3 & 4 & UK citizen & Nuclear family & Stages $1 \ddagger$ and $2 \ddagger$ \\
\hline P09 & $\begin{array}{l}\text { Non-malignant } \\
\text { illness }\end{array}$ & $51-60$ & Male & Muslim & $1,1,1$ & 4 & UK citizen & Nuclear family & $\begin{array}{l}\text { Stages 1‡, 2, and } \\
3 \ddagger .\end{array}$ \\
\hline $\mathrm{P} 10$ & $\begin{array}{l}\text { Non-malignant } \\
\text { illness }\end{array}$ & $81-90$ & Male & Sikh & 3 & 2 & UK citizen & Extended family & $\begin{array}{l}\text { Stage 1†; patient } \\
\text { died }\end{array}$ \\
\hline P11 & Cancer & $61-70$ & Female & Sikh & 3,3 & 5 & Indian national & Extended family & Stages $1 \ddagger$ and $2 \ddagger$ \\
\hline P12 & Cancer & $61-70$ & Female & Sikh & $2,2,2$ & 4 & Indian national & $\begin{array}{l}\text { Lives with } \\
\text { spouse }\end{array}$ & $\begin{array}{l}\text { Stages } 1 \ddagger, 2 \text {, and } \\
3 \ddagger\end{array}$ \\
\hline P13 & Cancer & $30-40$ & Male & Muslim & $1,2,2$ & 3 & UK citizen & Nuclear family & $\begin{array}{l}\text { Stages } 1 \ddagger, 2 \text {, and } \\
3 \ddagger\end{array}$ \\
\hline P14 & $\begin{array}{l}\text { Non-malignant } \\
\text { illness }\end{array}$ & $61-70$ & Male & Muslim & $2,2,2$ & 4 & UK citizen & Extended family & $\begin{array}{l}\text { Stages } 1 \ddagger, 2 \text {, and } \\
3 \ddagger\end{array}$ \\
\hline P15 & $\begin{array}{l}\text { Non-malignant } \\
\text { illness }\end{array}$ & $51-60$ & Female & Muslim & 3,3 & 4 & UK citizen & Extended family & $\begin{array}{l}\text { Stages } 1 \ddagger \text { and } 2 \ddagger ; \\
\text { stage } 3 \text { carer only } \\
\text { interviewed }\end{array}$ \\
\hline P16 & $\begin{array}{l}\text { Non-malignant } \\
\text { illness }\end{array}$ & $71-80$ & Female & Muslim & 3,3 & 6 & UK citizen & Extended family & $\begin{array}{l}\text { Stage } 1 \ddagger \text {; stage } 2 \\
\text { carer only } \\
\text { interviewed }\end{array}$ \\
\hline P17 & $\begin{array}{l}\text { Non-malignant } \\
\text { illness }\end{array}$ & $51-60$ & Male & Sikh & 1 & 4 & UK citizen & Extended family & Stage 1 \\
\hline P18 & $\begin{array}{l}\text { Non-malignant } \\
\text { illness }\end{array}$ & $51-60$ & Female & Muslim & 2,2 & 5 & UK citizen & Alone & Stages 1 and 2 \\
\hline P19 & $\begin{array}{l}\text { Non-malignant } \\
\text { illness }\end{array}$ & $71-80$ & Female & Muslim & $4,3,3$ & 4 & UK citizen & Extended family & $\begin{array}{l}\text { Stages } 1 \ddagger, 2 \ddagger \text {, and } \\
3\end{array}$ \\
\hline P20 & Cancer & $41-50$ & Male & Muslim & 4 & 4 & UK citizen & Nuclear family & $\begin{array}{l}\text { Stage } 1 \ddagger \text {; patient } \\
\text { died }\end{array}$ \\
\hline P21 & Cancer & $71-80$ & Female & Muslim & 3 & 2 & UK citizen & Extended family & $\begin{array}{l}\text { Stage 1f; stages } 2 \\
\text { and } 3 \text { carer only } \\
\text { interviewed }\end{array}$ \\
\hline P22 & $\begin{array}{l}\text { Non-malignant } \\
\text { illness }\end{array}$ & $61-70$ & Female & Sikh & 1 & 5 & UK citizen & Nuclear family & Stage $1 \ddagger$ \\
\hline P23 & $\begin{array}{l}\text { Non-malignant } \\
\text { illness }\end{array}$ & $61-70$ & Male & Muslim & 3 & 4 & UK citizen & Extended family & $\begin{array}{l}\text { Stage } 1 \text {; patient } \\
\text { died }\end{array}$ \\
\hline P24 & $\begin{array}{l}\text { Non-malignant } \\
\text { illness }\end{array}$ & $71-80$ & Male & Sikh & 2 & 4 & UK citizen & $\begin{array}{l}\text { Lives with } \\
\text { daughter }\end{array}$ & $\begin{array}{l}\text { Patient not } \\
\text { interviewed } \\
\text { (dementia) }\end{array}$ \\
\hline P25 & $\begin{array}{l}\text { Non-malignant } \\
\text { illness }\end{array}$ & $30-40$ & Female & Muslim & 2,2 & 5 & UK citizen & Nuclear family & Stages 1 and 2 \\
\hline
\end{tabular}

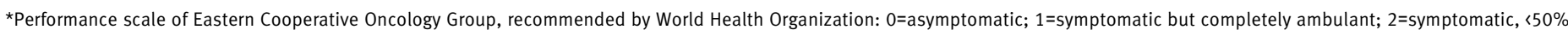
of time in bed during day; $3=$ symptomatic, $>50 \%$ of time in bed, but not bed bound; $4=$ bed bound; $5=$ death

†Carstairs' deprivation index for Scottish postcode sectors 2001: $1=$ most affluent, $7=$ most deprived. ${ }^{31}$

$\ddagger$ Patient and carer interviewed jointly. 
It was evident from the responses of patients, family carers, and professionals that the barriers to accessing end of life care arose from the perceptions and beliefs of ethnic minority communities about death and dying and end of life care, in the inflexibility of services, and in the attitudes of service providers.

\section{Barriers among patients and families}

Box 6 summarises the barriers to accessing appropriate care among patients and families. Planning effective end of life care was difficult when there was a lack of open discussion about dying. Families sometimes controlled information, especially when they acted as interpreters between the patient and health professionals. This created tension for health professionals, as most subscribed to a philosophy of openness. For example, when oncology staff wanted to tell a patient she had cancer and why she was receiving chemotherapy, the carer insisted that her mother, who spoke no English, was not told the diagnosis as she feared her mother would "totally give up" (carer 11). Even in the hospice setting this perception could lead to family members asking for information to be withheld: a woman who acted as an interpreter for her husband did not want hospice staff to discuss his poor prognosis; it was apparent from the interview with the patient, however, that he had a much clearer idea of his prognosis than the carer suggested:

"I said to them 'don't tell him how long,' but they said if he asks any questions, they'll have to tell him. He never asked." (Carer 20, wife of Muslim patient with cancer, stage 1 interview)

In a separate interview, the patient said:

"Everything is finishing now, nothing works . . . [crying]. I don't know what to do. I've got five daughters, who is going to provide for them? I don't know what to do. What will they do? There is nothing else they [the hospice] can do-no cure." (Patient 20, Muslim man with cancer, stage 1 interview)

Other patients perceived the hospice as "somewhere to go to die." While not unusual in the general population, this view was widespread among patients and carers in our study, with the perception of cultural inappropriateness presenting an additional barrier:

"I think the reason people don't like to go to hospice is because of the cultural differences and people tend to feel isolated, due to lack of own food, language, and television. It's different down in England as the hospices are run by Asian for the Asian." (Carer 22,

\begin{tabular}{|c|c|c|c|c|}
\hline Participant & Nominated family carer & $\begin{array}{l}\text { Timing of interviews with } \\
\text { family carer }\end{array}$ & $\begin{array}{l}\text { Nominated professional } \\
\text { carer }\end{array}$ & $\begin{array}{l}\text { Timing of interviews with } \\
\text { professional carer }\end{array}$ \\
\hline P01 & Wife & $\begin{array}{l}\text { Stage } 1^{*} \text { and at } \\
\text { bereavement }\end{array}$ & $\begin{array}{l}\text { Social worker, palliative } \\
\text { care specialist }\end{array}$ & $\begin{array}{l}\text { Stages } 1 \text { and } 2 \text { and after } \\
\text { death }\end{array}$ \\
\hline P02 & Wife & Stage $1^{*}$ & General practitioner & Stage 1 and after death \\
\hline P03 & None & 0 & Oncologist & Stages 1-3 \\
\hline P04 & Husband & 0 (declined) & Occupational therapist & Stage 1 \\
\hline P05 & Husband & Stage $1^{\star}$ & Social worker & Stage 1 \\
\hline P06 & None & 0 & Manager & Stage 2 \\
\hline P07 & Daughter & 0 (declined) & General practitioner & Stage 1 \\
\hline P08 & Daughter & Stages $1^{\star}, 2^{\star}$, and 3 & General practitioner & Stage 1 \\
\hline P09 & Wife & Stages $1^{\star}, 2,3$ & General practitioner & Stage 1 \\
\hline P10 & Son & Stages $1^{\star}$ and 2 & 0 & \\
\hline P11 & Daughter & Stages $1^{\star}, 2^{\star}$, and 3 & General practitioner & Stage 3 \\
\hline P12 & Husband & Stages $1^{\star}$ and $3^{\star}$ & 0 & \\
\hline P13 & Wife & Stages $1^{\star}$ and $3^{*}$ & Oncologist & Stage 3 \\
\hline P14 & Wife & Stages $1^{\star}$ and $3^{\star}$ & General practitioner & Stages 1 and 3 \\
\hline P15 & Daughter-in-law & Stages $1^{\star}, 2$, and 3 & General practitioner & Stages 1 and 3 \\
\hline P16 & Daughter-in-law & $\begin{array}{l}\text { Stages } 1^{*} \text { and } 2 \text { and } \\
\text { bereavement }\end{array}$ & General practitioner & Stage 2 \\
\hline P17 & None & 0 & 0 & \\
\hline P18 & Daughter & 0 (declined) & General practitioner & Stage 1 \\
\hline P19 & Daughter-in-law & Stages $1^{\star}, 2^{\star}$, and 3 & General practitioner & Stages 1 and 3 \\
\hline P20 & Wife & $\begin{array}{l}\text { Stage } 1^{*} \text { and at } \\
\text { bereavement }\end{array}$ & $\begin{array}{l}\text { Palliative care nurse } \\
\text { specialist }\end{array}$ & Stage 1 \\
\hline P21 & Daughter-in-law & Stages $1^{\star}, 2$ and 3 & General practitioner & Stage 3 \\
\hline P22 & Husband & Stage $1^{\star}$ & 0 & \\
\hline P23 & Wife & At bereavement & General practitioner & Stage 1 and after death \\
\hline P24 & Daughter & Stage 1 & 0 & \\
\hline P25 & None & 0 & General practitioner & Stage 2 \\
\hline
\end{tabular}


wife of Sikh patient with non-malignant illness, stage 1 interview)

A few patients found it challenging to accept personal care from non-Asian caregivers; concerns were expressed about privacy and cultural misunderstandings. Prejudices about different standards of behaviour and cleanliness of white people were also apparent:

"I will never allow them to do my cooking... We don't even know what they've eaten before they came to see me, or even if they've washed their hands after they use the toilet ... how can we rely on them?" (Patient 18, Muslim woman with non-malignant illness, stage 1 interview)

Box 3: Main themes common to this study and other end of life studies in general population $^{1617202532-35}$

Patients' and family carers' main concerns

- Pain and physical symptoms

- Reduced mobility and increasing dependency; dread of decline

- Conflicting emotions: anger, despair, guilt, optimism, hope, fear, low mood, resignation

- Social consequences of life limiting illness: loss of roles and relationships

- Patients' guilt for the distress and disruption caused by their illness; carers' responsibility and guilt towards the patient

- Burden, isolation, anxiety, and depression among carers

Faith and coping

- Common coping strategies included positive thinking, fighting spirit, acceptance, denial, and humour

- Severe illness and suffering prompted a search for meaning and identity

- Seeking peace of mind: some with strong faith took comfort in the promised afterlife, but many were afraid of death and "the unknown"

- Despair and anger, often accompanied by guilt about being insufficiently positive in outlook

- Difficulties in providing end of life care within geographically and emotionally fractured families

- Many patients, particularly those with non-malignant illness, had limited support from community services

Death and dying

- Limited open discussion of death and dying

- Some patients had little understanding of the diagnosis and prognosis, creating difficulties in planning effective end of life care, particularly in patients with nonmalignant illness

- Limited public understanding of palliative care (hospices were often perceived by patients and families as a place to die), creating barriers to access

\section{Service provision}

- Potential limited access to specialist palliative care services for those with a nonmalignant illness, people in remote and rural areas, older people, and the least affluent groups

- Wide variability in standards of generalist palliative care in primary and secondary care and care homes

- Service inflexibility in response to atypical and unpredictable needs

- Professionals advocated an open, partnership approach where they are willing to take advice from patients and carers

- Marked benefits for patients who experienced effective advocacy by service providers, including service coordination, provision of information, and liaison with other services —but many patients had no such support
Patients and families sometimes perceived prejudice from service providers in terms of rudeness, lack of sensitivity, or lack of interest:

“The nurses get angry at me ... I don't know whether they treat our people that way or if it's everyone." (Carer 8, daughter of Muslim man with non-malignant illness, stage 2 interview)

"The staff's attitude was basically when are you going to take him home, as if he was one patient too many to look after. I'm sure if he was white, nobody would have said that, take him home." (Carer 23, wife of Muslim patient with non-malignant illness, stage 2 interview)

Perceived discrimination by service providers and concern about what others in their own community would say contributed to reluctance to seek help, particularly financial support and help with personal care:

"If we ask for help from outside, what would others say? They would say that she could not take care of her father in law." (Carer 10, daughter-in-law of Sikh man with non-malignant illness, stage 1 interview)

Inability to speak English was perceived as a major disadvantage in accessing services, applying for benefits, forming relationships with professionals, and negotiating care options. It also meant that bereavement could be a particularly isolating experience for carers who did not speak English and lacked social or professional support.

\section{Barriers among professionals}

Box 7 summarises the barriers among professionals. The low number of patients from ethnic minority groups accessing palliative care was recognised but not well understood:

"I would like to see them [Asian patients] being referred to us more often and I don't understand why they are not. There must be many more patients out there." (Patient 1, health professional interview)

Most healthcare and social care professionals expressed good intentions in striving to provide equitable care but were concerned by their lack of cultural understanding and were uncertain about how to adapt their usual care. Other professionals were anxious about making a cultural blunder, particularly in fraught end of life situations. A lack of understanding and awareness of cultural needs was acknowledged:

"Not knowing much about the religion ... that is sometimes difficult because you don't really know what you are talking about . . . maybe if I had known more about that then I could have been more help to him." (Patient 20, interview with professional after death)

"We had an issue with a [Asian] family who wanted to care for their mum at home ... the family wanted to do everything... That can sometimes be difficult for our 
Box 4: Main themes more evident in the South Asian population than general population

\section{Faith and coping}

- Illness and suffering viewed as God's will and a test of faith

- Struggle to reconcile present suffering with the promise of a good afterlife

- God's approval sought through positive thinking and actions

- Despair and anger seen as spiritual deficits and therefore emotional problems difficult to acknowledge openly

Death and dying

- Less open discussion of death and dying within families, even among patients with cancer

- Hospices perceived as culturally inappropriate for South Asian people

\section{Service provision}

- Basic needs, such as culturally acceptable food and culturally sensitive personal care, not always met by services

- Institutional or overt personal racism sometimes apparent in patients' and carers' interactions with services

- Poor service provision sometimes perceived as racially motivated when there was little evidence that this was the case

- Some patients and families were reluctant to seek help from services they perceived as racist, or because they had poor experience of services or were concerned about criticism from own community

- Inadequate professional training in diversity and concern about causing offence through lack of cultural understanding

- Some staff awareness of the needs of Sikh and Muslim patients but uncertainties about how to adapt usual care to a different cultural context

- Professionals uncertain about accurate, complete, and effective communication when patients or family members acted as interpreters

- Specialist palliative care accessed by few patients, even those with cancer

- Exceptional willingness and adaptability of hospice staff to meet the needs of Sikh and Muslim patients

district nurses in any palliative care, terminal care environment. But there was also the 'ooh am I doing something wrong, or that is unacceptable to them?' and yet nobody says 'that is unacceptable.' They say 'no, no we will do it our way' and it could have been a joint learning experience. But it is difficult to learn within a very difficult situation." (Patient 18, interview with professional)

"Social [needs] I obviously enter into. Spiritual things I don't because I am an atheist myself and I don't enter into any of this nonsense whatsoever. You people go and see their priests or preachers or whatever... I don't discuss that at all." (Patient 8, interview with professional)

Many professionals interviewed were unaware of any training in diversity and cultural awareness available to them, and others suggested that existing approaches were ineffective in changing services and attitudes:

"There are things that are supposed to be happening in relation to Fair for All, equality and diversity, all these fine words, but you do begin to wonder, it is fine rhetoric and nobody is disagreeing with it, but on the shop floor it is not making a huge amount of difference." (Patient 6, interview with professional)

Institutional discrimination also created a barrier. Services often had difficulty managing basic needs such as communication with non-English speakers, the halal diet (that which is allowed in Islam), and need for specific hygiene practices, such as wudu (ritual ablution preceding daily prayers) and istinja (washing with free flowing water after urination or a bowel movement). At times care was clearly culturally insensitive. For example, one female Muslim patient had to accept help with toileting from male nurses when no female nurses were on duty and felt humiliated:

\footnotetext{
"There were only two males in the department so what do you do then? [sounding anxious] I had to get help but they said 'we won't look' but look is not everything, you can feel as well. What organs is where, what part of your body, he just has to visualise it, don't have to look." (Patient 4, Muslim woman with non-malignant illness, stage 2 interview)
}

Trying to organise interpreters at short notice-for example, to attend a house call with a general practitioner - was seen by service providers as impossible. In some cases the patient was required to translate between the health professional and the family, creating problems at the very end of life:

\footnotetext{
"One of the great concerns I have is house calls, where the only person who is able to speak in English is the patient who is dying. That is not useful in that the input that I could give in support to the rest of the family is much more restricted because it is only the patient who is the conduit for passing on the information. I don't think that is always the best thing." (Patient 2, interview with professional)
}

Services were often reactive rather than based on needs, with little flexibility about timing or roles performed. They therefore struggled to meet complex or variable needs. Constraints on resources were obvious, and reliance on family carers was overtly acknowledged:

"Part of the problem is that we wait until the problems arise and we don't even look for problems - we wait for 
Box 5: Key features of effective care

- A partnership approach between a key professional and the patient, with mutual acknowledgment of expertise and professionals willing to ask patients and families for advice about culturally appropriate care

- Well organised, multidisciplinary, anticipatory planning of care, with regular monitoring and appropriate referrals

- Good communication based on openness and willingness to address difficult subjects

- Responsiveness and flexibility in trying to meet needs

- Continuity of care

- Support for carers, with acknowledgment of their role and negotiation between services and family carers

families to tell us themselves and complain.”(Patient 5, interview with social care professional)

\section{Overcoming barriers: an illustration of discrimination and} effective advocacy

A Sikh patient with multiple long term conditions, who was homeless and an asylum seeker, complained of rude, hostile attitudes by staff, neglect of his needs, continually receiving inappropriate food, and feeling humiliated by staff hostility if he complained about the food or asked questions about his treatment:

\begin{abstract}
"One of the nurses said to me that 'I will paint a horrible picture of you and report you to the immigration and they will deport you,' that's how they treat me." (Patient 6, Sikh man with non-malignant illness, stage 1 interview)
\end{abstract}

\section{He described how Asian staff advised him:}

"They tell me to keep smiling all the time. They tell me that you should be grateful because you are receiving free of charge treatment which would not be possible in [own country]."

The professional interviewed confirmed that his care had been poor, his dietary needs unmet, and his treatment discriminatory:

"It did appear to me that some of the clinicians and managers who had a clinical background, in my view probably should have known better, seemed to be suggesting that they send him back to [own country] as soon as they possibly could, apparently without any notion of the consequences." (Patient 6, interview with professional)

\section{Box 6: Patient and family barriers to accessing appropriate care}

- Lack of open discussion about death and dying

- Negative perception of hospices, with few having experience of a hospice

- Stereotypes and prejudices about receiving care from people from a different culture

- Reluctance to ask for help

- Language
The professional adopted an advocacy role for the patient's needs, addressed his problems with the hospital food, helped him with access to welfare rights and benefits, and liaised with ward staff on his behalf. His care was subsequently taken over by a different clinical team, with whom he had good relationships, and he became much happier and expressed confidence in the clinical team and gratitude for his treatment:

"Everything is fine now, I'm well cared for." (Patient 6, stage 2 interview)

\section{Vulnerability}

It was apparent that the most assertive patients and families, articulate in English, and those with a good advocate were able to access services more effectively than those who were less able to assert their needs. One participant said:

"For people in our situation-born and brought-up here-we're really no different to the masses, really are we? We're able to communicate, we're able to express our opinion, we're able to demand if we think something's not right, we can have it put right." (Patient 3, Muslim woman with cancer, stage 2 interview)

In contrast we found that recent migrants and those with poor English language skills, no family advocate, and dying of non-malignant diseases were less able to articulate their needs and negotiate care options and therefore overcome the barriers identified. Two were asylum seekers, living in temporary housing, with uncertain status, with no extended family or community support. Others were receiving benefits, and many described everyday racial abuse and harassment, contributing to a sense of alienation.

\section{DISCUSSION}

This study has found that end of life care remains substandard for many South Asian Sikh and Muslim patients, particularly the most vulnerable. Exploring the end of life needs of ethnic minority and faith communities qualitatively over time from patient, family carer, and professional perspectives offers important new insights. Previous studies have found that palliative care services are not culturally sensitive. ${ }^{23}$ The risk of cultural misunderstandings around end of life care may grow with increasing heterogeneity of ethnic and religious groups ${ }^{36}$ but there is also potential for increased understanding and integration.

Over a decade on from the seminal Opening Doors report, ${ }^{14}$ services still have difficulty in meeting nonmainstream end of life needs effectively. Feelings of exclusion from mainstream society and services are an additional previously unrecognised barrier to access. ${ }^{37}$ Services were often inflexible and unable to respond effectively when faced with "atypical" needs-for example, culturally appropriate food or sex specific 
Box 7: Barriers among professionals

- Lack of cultural awareness and understanding of needs

- Fear of making a cultural blunder

- Cultural assumptions, particularly about family

- Lack of effective cultural awareness or training in diversity

- Institutional discrimination and direct racism

- Language barriers and inability to access interpretation services at short notice

- Inflexible services provide good care for people from ethnic minority groups. ${ }^{42}$ Professionals in our study stressed their desire to deliver culturally competent care, but also expressed uncertainties about cultural aspects of complex end of life care. Our experiences suggest that "real time" advice on appropriate responses, where professionals could discuss an individual patient at the time they are providing care, would be helpful in building the skills and confidence to deliver culturally sensitive palliative care to an increasingly diverse population.

Equitable access to appropriate end of life care is not merely an issue for people from ethnic minority groups and faith backgrounds. Unmet needs and unequal access to palliative care services have been reported in people with non-malignant illness, ${ }^{202533}$ those living in less affluent circumstances, ${ }^{17344344}$ those in rural areas, ${ }^{1645}$ and older people. ${ }^{164647}$ Variability in quality of service provision, and barriers such as lack of service flexibility and lack of open discussion about approaching death are not unusual in the general population. ${ }^{45}$ People from ethnic minority backgrounds may perceive inadequacies in services as based on racism when the problem is a generally poor service. Improving access to palliative care for all-particularly those with non-malignant illnesses - as well as focusing on the specific needs of ethnic minority groups is therefore required.

\section{Strengths and limitations}

The complexities of carrying out research at the end of life and research with ethnic minority groups and faith groups are well known, with particular challenges around recruitment. ${ }^{1335}$ This in-depth longitudinal end of life study of these "hard to reach" populations resulted in a rich description of experiences of illness and service provision over time. ${ }^{48}$ Our theoretically informed approach, enhanced by interviewing patients, carers, and key professionals, enabled us to gain insights that would have been unavailable through single interviews - for example, the experiences of the Sikh man whose discriminatory care was transformed by a committed individual adopting an advocacy role. The methodological approach also enabled us to identify the direct, rather than perceived, discrimination this case exemplifies, by interviewing the key professional. Additional strengths include the high proportion of participants that agreed to participate $(96 \%)$ and the high retention rate, with most attrition occurring because of death.

Finding potential participants was, as anticipated, difficult. Identifying people at the end of life is complex owing to difficulties in prognosticating, particularly in non-cancer illness; therefore a few patients recruited were not, it emerged, in the last year of life. Although we recruited participants of various ages and socioeconomic backgrounds, with a variety of conditions and severity of disease, and had a high recruitment rate, it is difficult in qualitative studies of this kind to be certain of the broader generalisability of our findings. But by linking our in-depth data with the theoretical literature and the team's comprehensive practical 


\section{WHAT IS ALREADY KNOWN ON THIS TOPIC}

People from ethnic minority groups are less likely to access palliative care services than the majority population

Barriers to access include attitudes of the patient, family, and professionals

End of life needs in minority groups are poorly understood

\section{WHAT THIS STUDY ADDS}

Within ethnic minority groups the most vulnerable people, such as recent migrants, have the poorest access to services

Active case management of high risk patients should help to overcome many of these barriers

Professionals need ready access to information and support specific to an individual patient and family vulnerable patients, assessment of their needs, and provision of better care. Individual case management based on recognition of vulnerability may be a key to more equitable service provision, not just for ethnic minority groups but for all those who have poor access, including lower income groups and those with nonmalignant illness. Improving care for ethnic minority groups involves partnership working where professionals are able to acknowledge their lack of knowledge and expertise in cultural practices and take advice from patients, families, and community groups. Active outreach and community development with South Asian communities should help to raise awareness and overcome misconceptions of palliative and hospice care; such initiatives could, for example, include hospice open days, staff visiting religious and community centres, or interacting with local South Asian media outlets. Engagement of interpreting services should replace reliance on communication with the patient solely through the family. A need also exists to appreciate better the situations in which such interpreter input is non-negotiable, such as taking consent.

A change in emphasis is needed in the education and training of cultural awareness or diversity to move it away from the lecture theatre and out to service providers, with in-house, multidisciplinary, practice based, case based training in primary care, social services, hospitals, and hospices. Involving patients and members of communities in the delivery, evaluation, and support of professional training is important. In UK primary care, points from the quality outcomes framework (and hence reimbursement) are now available for significant event analysis ${ }^{51}$ where care teams are encouraged to reflect on real cases and to identify strengths and weaknesses in care provided. This could be adapted to diversity training, with facilitation from an expert in the discipline.

Greater emphasis on culturally appropriate end of life care, incorporating spiritual aspects, is needed in undergraduate and postgraduate curriculums, for health and social care professionals, and for care staff. Education and training based mainly on descriptions of differences run the risk of reinforcing stereotypes; awareness of cultural complexity and practitioners' self reflection should therefore be core aspects of education. ${ }^{5253}$ Resources are available to support clinicians and educators in developing cultural competence, including the NHS ethnicity and health specialist library (www.library.nhs.uk/ethnicity). ${ }^{13653}$

Understanding patients' needs is a prerequisite for services to be able to adapt to meet them..$^{50}$ The lack of national data on access to services by various groups creates difficulties in measuring progress in policy implementation. This study suggests that a considerable gap remains between the good intentions of many professionals and of social inclusion policy and the realities of service provision. ${ }^{13}$

\section{Implications for policy, practice, and research}

Building on this in-depth qualitative work, research needs to develop and evaluate multifaceted interventions aimed at improving identification of the most

\section{Conclusions}

Policy directives aimed at improving access to services and standards of care for ethnic minority groups in Scotland are laudable. ${ }^{13}$ It seems, however, that end of life services for South Asian Sikh and Muslim patients remain wanting in many key areas. Our findings indicate that professionals recognise these shortcomings and would be receptive to initiatives focused on improving service delivery for these populations. More individualised care prioritising the needs of the most vulnerable patients and carers and making available 
real time support and advice for healthcare and social care professionals are likely to be particularly effective strategies for improving care and tackling inequalities, so ensuring better outcomes for patients.

We thank the patients, family carers, and professionals who participated in the studies; those who helped with recruitment; and Shahida Shah for secretarial support.

Contributors: AS conceived the study and all grant holders (AS, AW, SM EG, MK, RB, JL, DB, JA, and RG) developed the design. TI and AW collected and analysed the data, with support from all grant holders. AW and AS drafted the paper. All authors revised and edited the paper. AS is guarantor.

Funding: Chief Scientist Office, Scottish Government Health Department. The research team is independent of the funders and the views expressed are those of the researchers, not the funding body.

Competing interests: None declared.

Ethical approval: This study was approved by Lothian research ethics committee and NHS research and development.

1 Gatrad R, Brown E, Sheikh A, eds. Palliative care for South Asians: Muslims, Hindus and Sikhs. London: Quay Books, 2007.

2 Gunaratnam Y. Improving the quality of palliative care. London: Race Equality Foundation, 2007.

3 Firth S. Wider horizons. Care of the dying in a multicultural society. London: National Council for Hospice and Specialist Palliative Care Services, 2001.

4 Gatrad AR, Brown E, Notta H, Sheikh A. Palliative care needs of minorities. BMJ 2003;327:176-7.

5 Clark J. Patient centred death. BMJ 2003;327:174-5.

6 Sheikh A, Gatrad AR, eds. Caring for Muslim patients. 2nd ed. Oxford: Radcliffe, 2008.

7 Sheikh A. Should Muslims have faith based health services? BMJ 2007;334:74.

8 Shi L, Stevens GD. Vulnerability and unmet health care needs. The influence of multiple risk factors. J Gen Intern Med 2005;20:148-54.

9 Szczepura A. Access to health care for ethnic minority populations. Postgrad Med J 2005;81:141-7.

10 Netuveli G, Hurwitz B, Levy M, Fletcher M, Barnes G, Durham SR, et al. Ethnic variations in UK asthma frequency, morbidity and health service use: a systematic review and meta-analysis. Lancet 2005;365:312-7.

11 Krakauer EL, Crenner C, Fox K. Barriers to optimum end-of-life care for minority patients. J Am Geriatr Soc 2002;50:182-90.

12 Sultana K, Sheikh A. Most UK datasets of routinely collected health statistics fail to collect information on ethnicity and religion. / $R$ Soc Med 2008;101:463-5.

13 Bhopal R. Ethnicity, race and health in multicultural societies. Oxford: Open University Press, 2007.

14 Hill D, Penso D. Opening doors: improving access to hospice and specialist palliative care services by members of black and ethnic minority communities. London: National Council for Hospice and Specialist Palliative Care Services, 1995.

15 Karim K, Bailey M, Tunna K. Non-white ethnicity and the provision of specialist care services: factors affecting doctors' referral patterns. Palliat Med 2000;14:471-8.

16 Ahmed N, Bestall JC, Ahmedzai SH, Payne SA, Clark D, Noble B. Systematic review of the problems and issues of accessing specialist palliative care by patients, carers and health and social care professionals. Palliat Med 2004;18:525-42.

17 Koffman J, Burke G, Dias A, Raval B, Byrne J, Gonzales J, et al. Demographic factors and awareness of palliative care and related sevices. Palliat Med 2007;21:145-53.

18 Merrell J, Kinsella F, Murphy F, Philpin S, Ali A. Accessibility and equity of health and social care services: exploring the views and experiences of Bangladeshi carers in South Wales, UK. Health Soc Care Community 2006;14:197-205.

19 National Black Carers and Carers Workers Network. Beyond we care too. Putting black carers in the picture. London: Afiya Trust 2008.

20 Murray S, Boyd K, Kendall M, Worth A, Benton TF, Clausen H. Dying of lung cancer or cardiac failure: prospective qualitative interview study of patients and their carers in the community. BMJ 2002;325:929-32.

21 Murray S, Sheikh A. Palliative care beyond cancer: care for all at the end of life. BMJ 2008;336:958-9.

22 Elkan R, Avis M, Cox K, Wilson E, Patel S, Miller S, et al. The reported views and experiences of cancer service users from minority ethnic groups; a critical review of the literature. Eur / Cancer Care 2007;16:109-21.

23 Wild S, Fischbacher C, Brock A, Griffiths C, Bhopal R. Mortality from all cancers and lung, colorectal, breast and prostate cancer by country of birth in England and Wales, 2001-2003. Br J Cancer 2006;94:1079-85.
24 Nazroo J. Genetic, cultural or socioeconomic vulnerability? Explaining ethnic inequalities in health. Sociol Health Illn 1998;20:710-30.

25 Boyd K, Murray SA, Kendall M, Worth A, Benton TF, Clausen H. Living with advanced heart failure: a prospective, community based study of patients and their carers. Eur J Heart Fail 2004;6:585-91.

26 Sheikh A. Why are ethnic minorities under-represented in US research studies? PLoS Med 2006;3:e49.

27 Connill C, Verger E, Salamero M. Performance status assessment in cancer patients. Cancer 1990;65:1864-6.

28 Lingard L, Albert M, Levinson W. Grounded theory, mixed methods, and action research. BMJ 2008;337:a567.

29 Pope C, Ziebland S, Mays N. Qualitative research in health care: analysing qualitative data. $B M J$ 2000;320:114-6.

30 Scotland's Census 2001. General Register Office for Scotland, Edinburgh. 2008. www.scrol.gov.uk/scrol/browser/profile.jsp? profile $=$ Population\&mainArea $=$ Scotland $\&$ mainLevel $=$ CountryPro file.

31 Carstairs V, Morris R Deprivation and Health in Scotland. Aberdeen: Aberdeen University Press, 1991.

32 Exley C, Field D, Jones L, Stokes T. Palliative care in the community for cancer and end-stage cardiorespiratory disease: the views of patients, lay-carers and health care professionals. Palliat Med 2005;19:76-83

33 Seamark D, Seamark C, Halpin D. Palliative care in chronic obstructive pulmonary disease: a review for clinicians. / $R$ Soc Med 2007:100:225-33.

34 Kessler D, Peters T, Lee L, Parr S. Social class and access to specialist palliative care. Palliat Med 2005;19:105-10.

35 Kendall M, Harris F, Boyd K, Sheikh A, Murray S, Brown D et al. Key challenges and ways forward in researching the "good death": qualitative in-depth interview and focus group study. BMJ 2007;334:521-4.

36 Jones K. Diversities in approach to end-of-life: a view from Britain of the qualitative literature. J Res Nurs 2005;10:431-54.

37 Salway S, Platt L, Chowbey P, Harriss K, Bayliss E. Long-term ill health poverty and ethnicity. York: Joseph Rowntree Foundation, 2007.

38 Darzi A. High quality care for all: NHS next stage review final report. London: Department of Health, 2008.

39 Scottish Executive. Fair for all: working together towards culturally competent services. Edinburgh: Scottish Executive, 2002. [NHS HDL 200251$.

40 Kai J, Beavan J, Faull C, Dodson L, Gill P, Beighton A. Professional uncertainty and disempowerment responding to ethnic diversity in health care: a qualitative study. PLoS Med 2007;4:e323.

41 Kai J, Spencer J, Woodward N. Wrestling with ethnic diversity: toward empowering health educators. Med Educ 2001;35:262-71.

42 Richardson A, Thomas VN, Richardson A. "Reduced to nods and smiles": experiences of professionals caring for people with cancer from black and ethnic minority groups. Eur I Oncol Nurs 2006;10:93-101.

43 Davies E, Higginson IJ, eds. Palliative care. The solid facts. Copenhagen: World Health Organization, 2004

44 Higginson Il, Jarman B, Astin P, Dolan S. Do social factors affect where patients die? An analysis of 10 years of cancer deaths in England. / Public Health Med 1999;21:22-8.

45 Shipman C, Gysels M, White P, Worth A, Murray SA, Barclay S, et al. Improving generalist end of life care: national consultation with practitioners, commissioners, academics, and service user groups. BMJ 2008;337:a1720

46 Davies E, Higginson II, ed. Better palliative care for older people. Copenhagen: World Health Organization, 2004

47 Grande G, Farquhar M, Barclay S, Todd C. The influence of patient and carer age in access to palliative care services. Age Ageing 2006;35:267-73.

48 Murray S, Sheikh A. Serial interviews for patients with progressive diseases. Lancet 2006;368:901-2.

49 Owens A, Randhawa G. "It's different from my culture; they're very different": providing community-based "culturally competent" palliative care for South Asian people in the UK. Health Soc Care Community 2004;12:414-21.

50 Equalities Review. Fairness and freedom: the final report of the equalities review. London: Equalities Review, 2007. www.theequalitiesreview.org.uk.

51 Robinson L, Stacy R, Spencer J, Bhopal R. Use of facilitated case discussions for significant event auditing. BMJ 1995;311:315-8.

52 Webb E. Stereotypes and semaphore, leave them coming back for more, pieces missing, nothing fitting, complications galore. Arch Dis Child - Educ Pract 2005;90:11-4.

53 Kai J. Valuing diversity: a resource for health professional training to respond to cultural diversity, 2nd ed. London: Royal College of General Practitioners, 2006.

Accepted: 22 October 2008 